\title{
Transesophageal echocardiography imaging of subclavian to carotid artery transposition
}

\author{
Gary M. Dobson, MD • Randy D. Moore, MD • \\ Neal P. Maher, MD
}

Received: 3 January 2010/ Accepted: 10 March 2010/Published online: 24 March 2010

(C) Canadian Anesthesiologists' Society 2010

Paraplegia following endovascular management of thoracic aortic aneurysms is variably reported to occur in $2.7 \%$ (range $0-12 \%$ ) of cases and is believed to be secondary to reduction of anterior spinal artery flow and spinal cord ischemia. ${ }^{1}$ This complication occurs more frequently when the left subclavian artery (LSA) is covered, compromising anterior cord blood flow from the left vertebral artery. ${ }^{2}$ Prophylactic revascularization utilizing left common carotid artery (LCA) to LSA bypass/transposition has been reported to reduce the incidence of paraplegia, particularly during long segment stenting of the thoracic aorta.

A method for visualizing aortic arch branches with transesophageal echocardiography (TEE) has been described in which the LCA and the LSA were successfully identified in $98 \%$ and $100 \%$ of cases, respectively. ${ }^{3}$ Using a similar approach, we report a case in which flow through the LSA-LCA transposition is documented using TEE.

A 69-yr-old male presented with pseudo-aneurysmal degeneration of a type $\mathrm{B}$ dissection and required endovascular repair of his thoracic aorta. As the planned endovascular procedure would cover the origin to the LSA, the LSA was transposed and then anastomosed to the LCA.

Electronic supplementary material The online version of this article (doi:10.1007/s12630-010-9303-7) contains supplementary material, which is available to authorized users.

G. M. Dobson, MD $(\varangle)$ · R. D. Moore, MD · N. P. Maher, MD

Peter Lougheed Centre, Calgary, AB, Canada

e-mail: gary.dobson@ AlbertaHealthServices.ca
Two days following surgery, the patient developed back pain suggestive of impending rupture of his pseudo-aneurysm and underwent urgent stenting of his thoracic aorta. With TEE guidance, verification of the functioning transposition could be assured both before and following stent deployment (video; available as electronic supplementary material).

The preservation of collateral circulation to the spinal cord is essential if paraplegia is to be avoided in patients undergoing extensive stenting of the thoracic aorta. In cases requiring long thoracic endovascular repair where the origin of the LSA is covered, the presence of a functioning arterial bypass (Figure 1) helps preserve flow through the left vertebral artery and anterior spinal arterial network and reduces the incidence of paraplegia. In suitable patients, TEE can be used to confirm the presence of a functioning arterial conduit from the carotid artery to the subclavian artery.

Competing interests None declared.

\section{References}

1. Sullivan TM, Srdundt TM $3^{\text {rd }}$. Complications of thoracic aortic endografts: spinal cord ischemia and stroke. J Vasc Surg 2006; 43 Suppl A: 85A-8A.

2. Buth J, Harris PL, Hobo R, et al. Neurologic complications associated with endovascular repair of thoracic aortic pathology: incidence and risk factors. A study from the European Collaborators on Stent/Graft Techniques for Aortic Aneurysm Repair (EUROSTAR) registry. J Vasc Surg 2006; 46: 1103-10.

3. Salerno P, Jackson A, Shaw M, Spratt P, Jansz P. Transesophageal echocardiographic imaging of the branches of the aorta: a guide to obtaining these images and their clinical utility. J Cardiothorac Vasc Anesth 2009; 23: 694-701. 

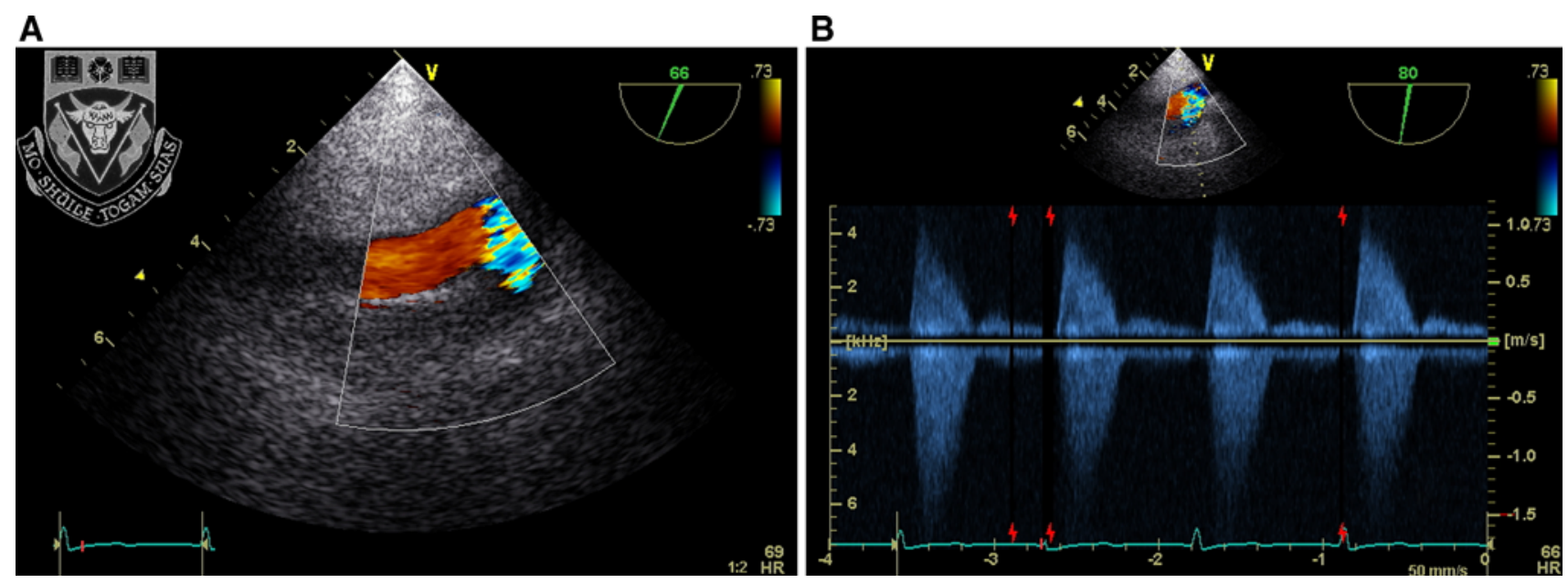

Fig. 1 A Colour Doppler image of insertion site of transposed subclavian artery acquired prior to stent deployment. B Pulse wave Doppler: Note presence of turbulence with both modalities 